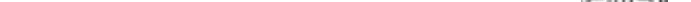





\section{Os Pankararu e o Associativismo Indígena na Cidade de São Paulo}

Marcos Alexandre dos Santos Albuquerque*

\section{"Eu Venho do Mundo"}

No relatório da Comissão Pró-Índio de São Paulo (2005, p. 05), segundo dados do IBGE, o número de indígenas que vivem na região metropolitana de São Paulo é de 59.989 indivíduos, o que dá ao estado paulista, em números, a terceira maior população indígena do país (atrás somente dos estados do Amazonas e da Bahia). As principais etnias que constituem essa população vieram migradas do nordeste brasileiro, como os Pankararu (PE), Fulni-ô (PE), Atikum (PE), Xurucu (PE), Kariri-Xocó (AL), Pankararé (BA) e Potiguara (PB). No Estado de São Paulo existe cerca de doze associações indígenas de diversas etnias. A maior parte das associações foi fundada de forma autônoma, com o intuito de fortalecer politicamente a demanda dessas populações pela assistência diferenciada garantida pelo estado aos povos indígenas (saúde, educação, preservação de patrimônio, território, moradia e outros).

A retórica destas associações enfatiza questões contemporâneas relacionadas à política oficial do estado. A principal delas é o discurso da proteção e preservação das tradições indígenas como retórica da ampliação da democracia e visibilidade da atuação do estado. As associações indígenas de São Paulo apelam a este tipo de tradição principalmente em duas circunstâncias: a) como espaço de receita econômica na apresentação de suas tradições em arenas específicas (museus, igrejas, universidades e outros); e, b) na conquista e geração de direitos indígenas junto aos órgãos públicos. Assim, a apresentação de tradições indígenas em arenas específicas acabou se tornando um novo, prestigiado e restrito espaço de mobilização coletiva e de visibilidade de um componente social e historicamente marginalizado.

* Doutorando no Programa de Pós-Graduação em Antropologia Social (PPGAS/UFSC). Membro do Laboratório de Estudos em Movimentos Étnicos (LEME/ UFCG); Antropologia Visual em Alagoas (AVAL /UFAL); Núcleo de Antropologia Visual e Estudos da Imagem (NAVI/UFSC); Grupo de Estudos sobre Rito e Performance (GESTO/ UFSC). marcosdada@yahoo.com.br 


\section{Os Pankararu da Comunidade Real Parque na cidade de São Paulo}

Os Pankararu formam uma população de aproximadamente 7.508 pessoas que habitam as Terras Indígenas Pankararu e Entre Serras (14.290 hectares), nos municípios de Petrolândia, Tacaratu e Jatobá, no sertão do estado de Pernambuco. Como grande parte da população migrante que fugiu das dificuldades econômicas do sertão nordestino em busca de melhores oportunidades de renda no sudeste do país, os Pankararu começaram a migrar para a cidade de São Paulo nos anos 1940, e mais intensamente, nas décadas de 1950-60 (Matta, 2006; 2007; Arruti, 1996; 1999). Desde então, essa migração se tornou constante e hoje há uma população fixa em São Paulo que soma mais de 2 mil pessoas, sendo que 509 moram numa favela no bairro do Real Parque, numa área nobre do Morumbi, à beira do rio Pinheiros. A principal atividade econômica de seus moradores vem do trabalho nessa região de São Paulo, para os homens principalmente como mão-de-obra na construção civil ou como vigilante, e para as mulheres no trabalho de "domésticas".

Do ponto de vista oficial - isto é, reconhecidos pela FUNAI do estado de São Paulo -, os indígenas que moram na capital não eram registrados porque não estavam em áreas indígenas (à exceção dos Guarani, que moram em três aldeias na periferia da cidade). Através da luta autônoma e da formação de associações, os indígenas vêm conseguindo acionar a lei e os órgãos públicos e conseguir parte da assistência diferenciada garantida pelo Estado (saúde, educação, preservação de patrimônio, território, moradia e outros). Por causa de sua mobilização, os Pankararu do Real Parque foram o primeiro grupo indígena residente em área urbana a ser reconhecido e ter assistência da FUNAI e da FUNASA em São Paulo (Sampaio, 2005).

Tal reconhecimento se deu pela criação, em 1994, da Associação S.O.S. Comunidade Indígena Pankararu. A Associação é, segundo o seu estatuto, uma entidade sem fins lucrativos para amparo e assistência de seus membros em diversas áreas (educação, alimentação, saúde, cultura, recreação e outras). Seus objetivos principais são o fortalecimento e melhoria das condições de vida das famílias indígenas por meio de projetos e atividades instrutivas e colaborar com os poderes públicos constituídos, no sentido de proporcionar aos membros associados informações e atendimento em tudo que se refere à atuação e competência da FUNAI e da FUNASA. O atual presidente da Associação S.O.S. Comunidade Indígena Pankararu é o Sr. Manoel Alexandre Sobrinho, conhecido por Bino (foto). 


\section{A Emergência do Praiá em São Paulo}

Na área Pankararu, em Pernambuco, o toré é o nome tanto de um ritual quanto de um tipo de dança e música. Os torés (músicas) são entoados na parte final de um ritual, ocasião que também é chamada de toré ou "brincadeira", espaço lúdico de participação coletiva. Já os praiás são as máscaras corporais que "vestem" os Encantados (entidades sobrenaturais) durante um ritual e para eles são dirigidos toantes (cânticos) próprios. Simplificando sobremaneira: o toré pode ser realizado fora da área Pankararu, como exibição de identidade e força política, enquanto os praiás, pelo seu caráter mais sagrado, ficam restritos às aldeias (Matta, 2006; 2007; Sandroni et. al., 2005; Arruti, 1996; 1999; Carneiro da Cunha, 1999).

Devido à hegemonia das representações que organizam o imaginário sobre o indígena em um modelo homogêneo (o índio genérico), e de suas tradições como consuetudinárias (ancestrais e anônimas), o praiá é o elemento que mais ganhou destaque nas apresentações públicas dos Pankararu em São Paulo. O Sr. Bino, presidente da Associação S.O.S. Comunidade Indígena Pankararu, mantém um grupo de exibição dos praiás que se apresenta em diversos lugares (escolas, igrejas, órgãos públicos, faculdades e outros). Em 1994, quando foi fundada a Associação Pankararu, havia somente um praiá em São Paulo, hoje são dez. Todos esses praiás foram tecidos (feitos) na aldeia, em Pernambuco, mostrá-los a um amplo público em São Paulo só foi possível com o consentimento dos caciques e pajés da aldeia.

A apresentação pública dos praiás como instrumento de visibilidade política e econômica na comunidade do Real Parque implica o problema de sua legitimidade. Ao darem visibilidade à sua condição social e reivindicarem a identidade de indígenas pela apresentação pública de uma tradição até então restrita à aldeia, os Pankararu construíram em uma situação e um local não usualmente indígenas, um espaço "para exibição de autênticas renovações culturais e de novas reflexividades sobre a identidade étnica" (Grünewald, 2004, p.11), implicando toda uma organização social na comunidade do Real Parque que constrói o espaço de negociação e transformação dos dogmas relacionados à unicidade, à sacralidade e à invisibilidade pública dos praiás. 


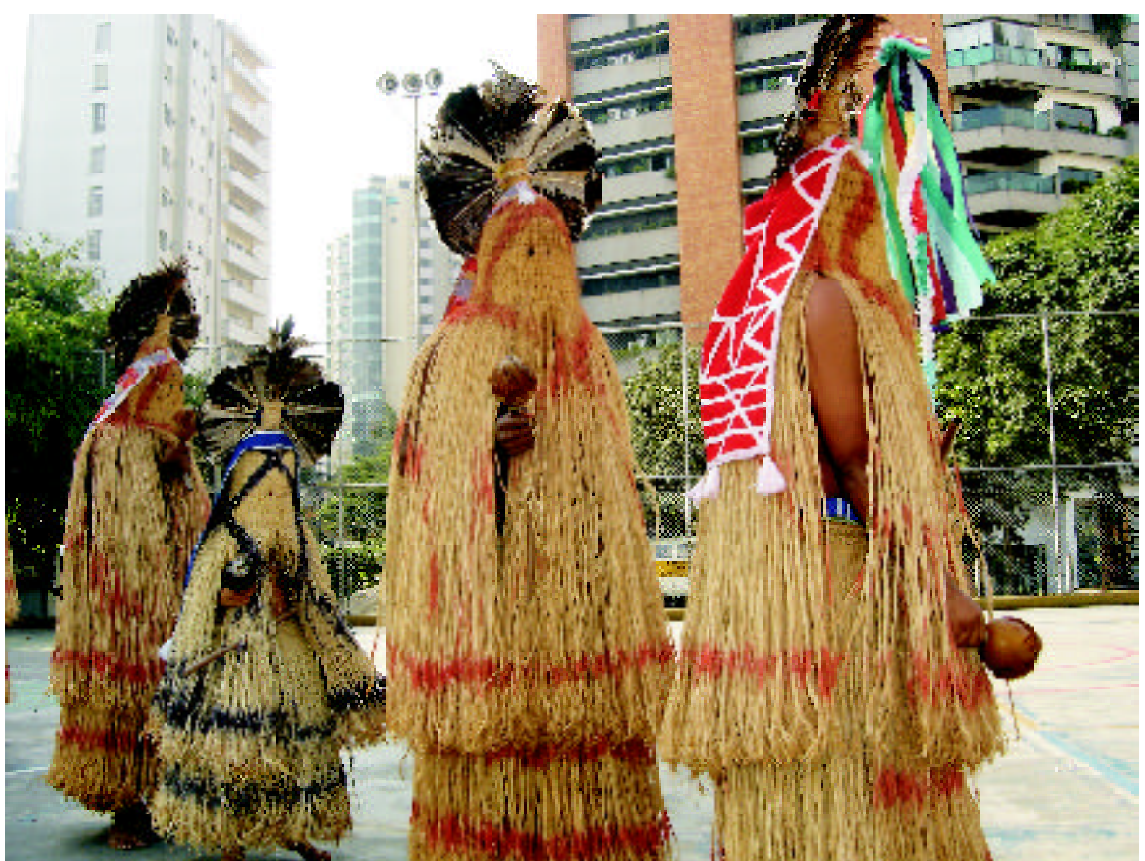

Figura 1: Eu venho do mundo.

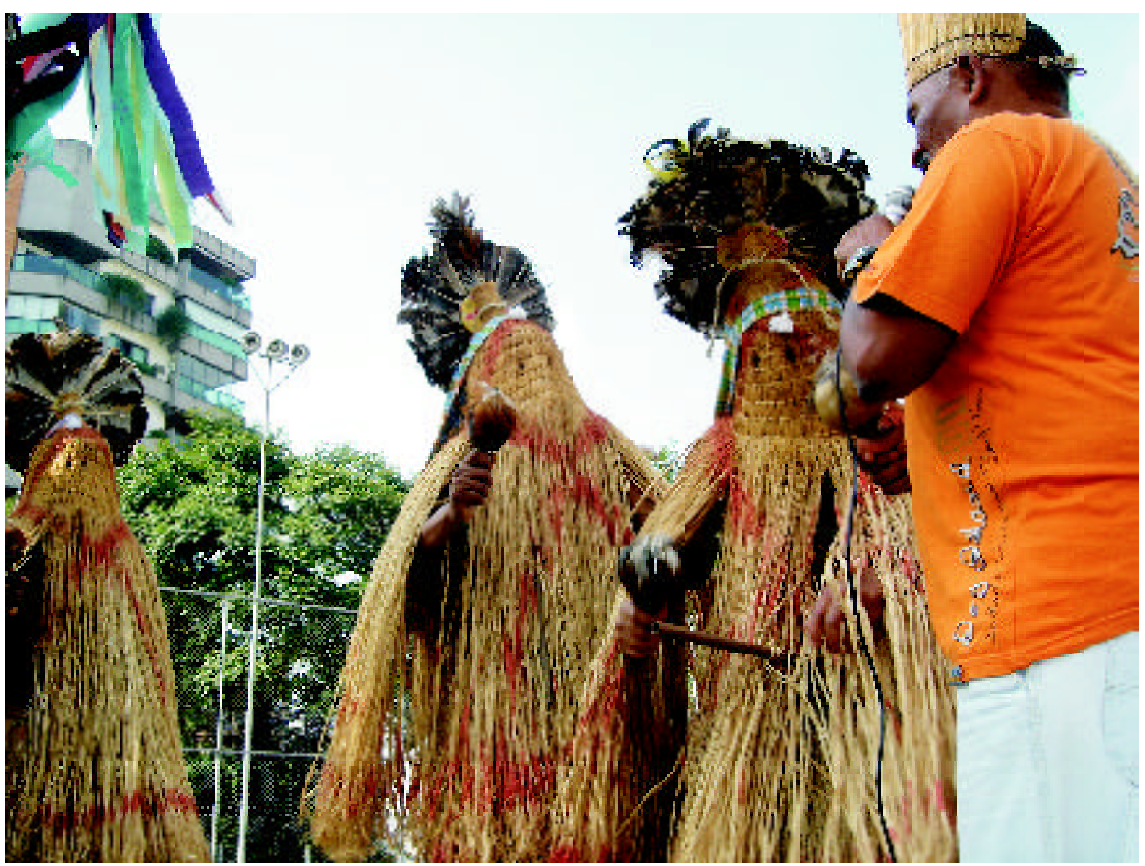

Figura 2: A emergência do Praiá em São Paulo.

232 Marcos Alexandre dos S. ALBUQUERQUE. Os Pankararu e o Associativismo... 


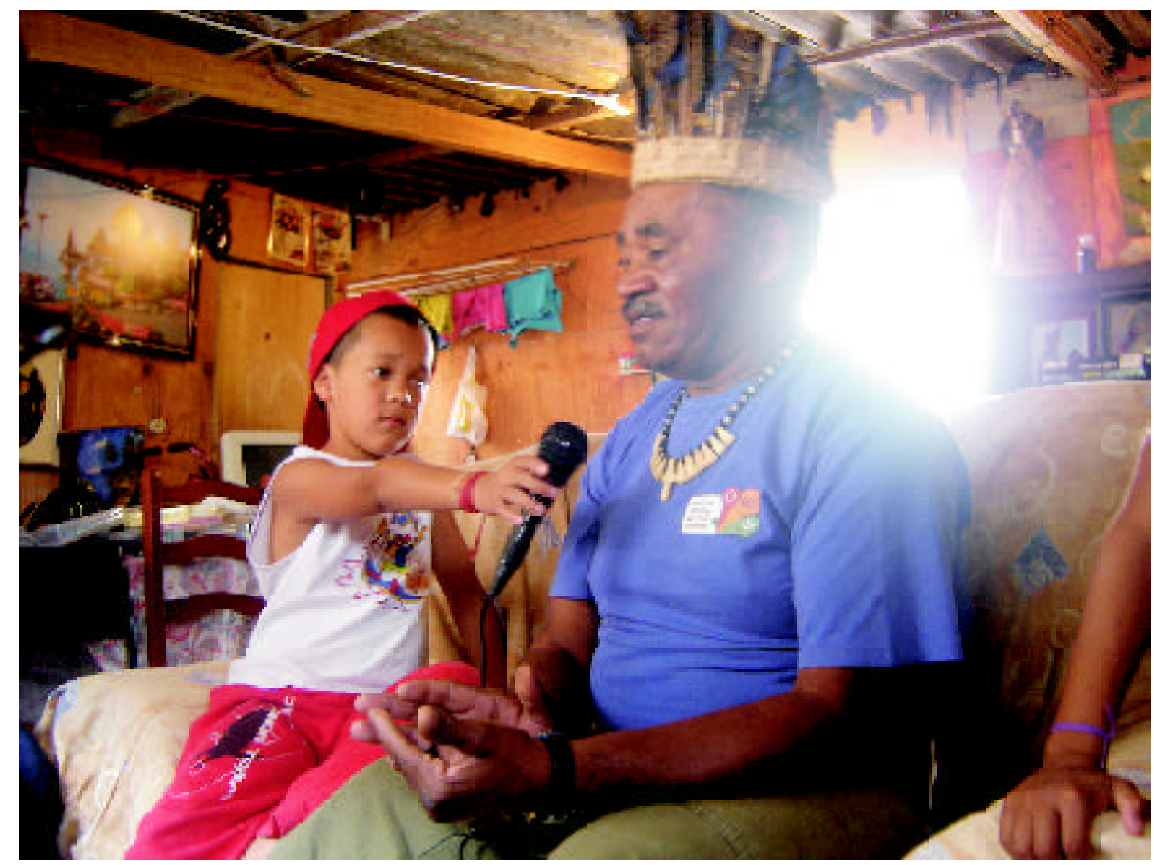

Figura 3: Sr Bino entrevistado pelo neto Tales, durante oficina de vídeo e nutrição - parceria com a ong Nossa Terra e Proj X.

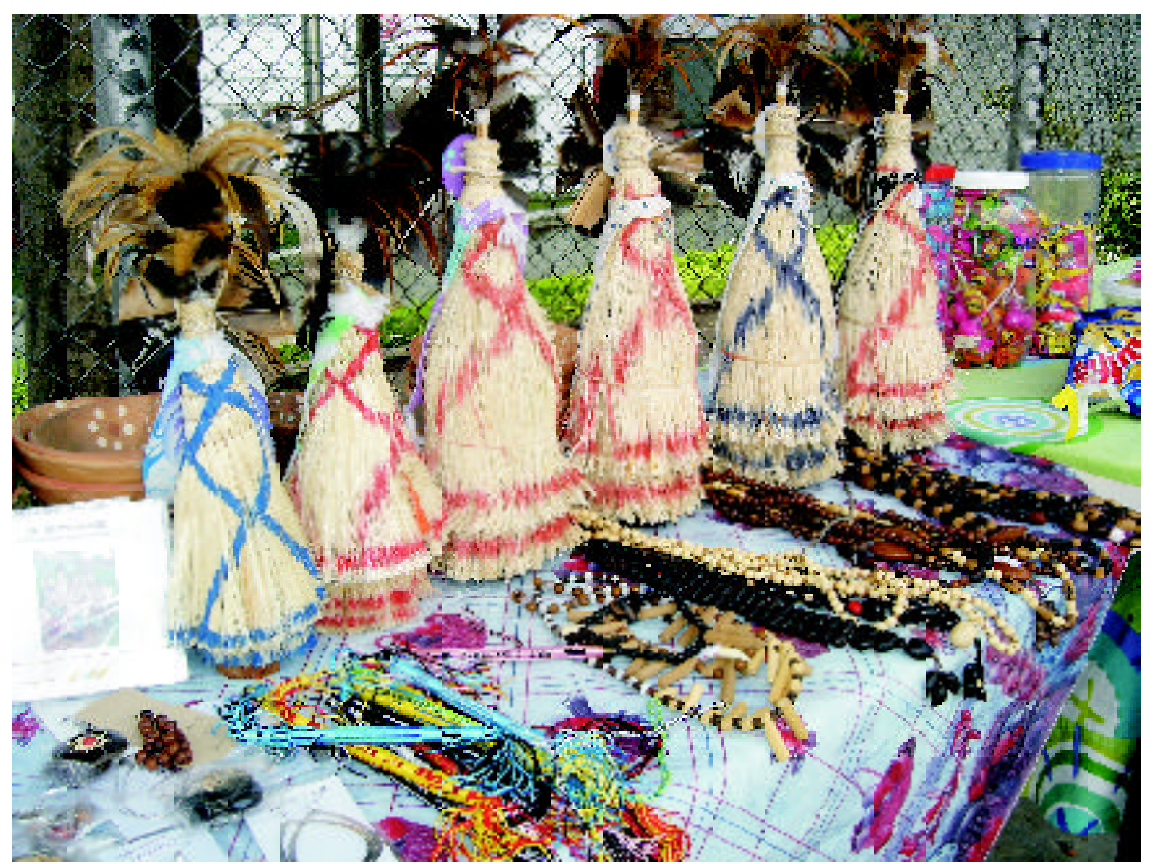

Figura 4: A emergência do Praiá em São Paulo. 


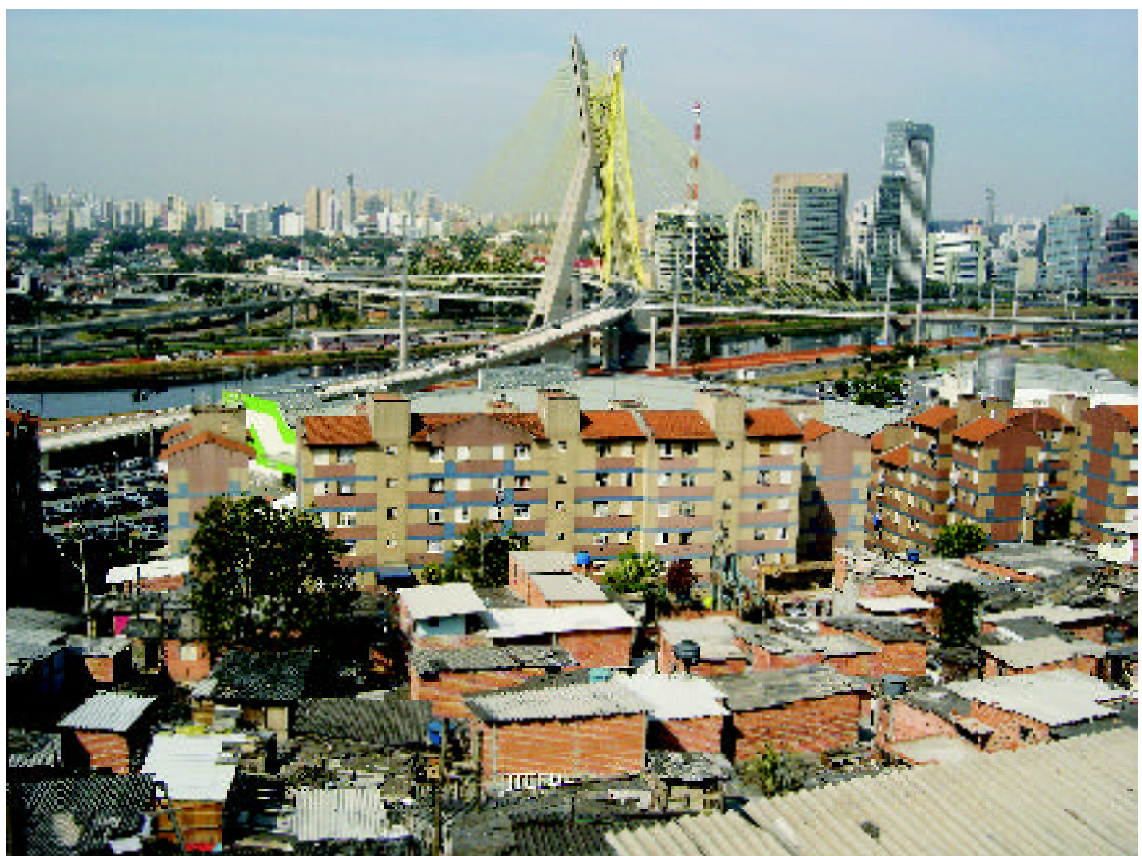

Figura 5: Comunidade do Parque Real - Morumbi, São Paulo.

\section{Referências}

ALBUQUERQUE, Marcos e NAKASHIMA, Edson (dir.). Eu venho do mundo. videodocumentário. Produção: Marcos Albuquerque, Edson Nakashima, Maria das Dores Conceição Pereira do Pardo, Associação S.O.S. Comunidade Indígena Pankararu, USP / UFSC / FAPESP. São Paulo, 2008. CD-Rom.

ARRUTI, José Maurício P. A. O Reencantamento do mundo: trama histórica e arranjos territoriais Pankararu. Dissertação (Mestrado em Antropologia Social) - PPGASMN/UFRJ, Rio de Janeiro, 1996.

. A árvore Pankararu: fluxos e metáforas da emergência étnica no sertão do São Francisco. In: OLIVEIRA, João Pacheco (org.). A viagem de volta. Etnicidade, política e reelaboração cultural no nordeste indígena. Rio de Janeiro: Contra Capa, 1999.

CARNEIRO DA CUNHA, Maximiliano. A Música Encantada Pankararu (toantes, toré, ritos e festas na cultura dos indios Pankararu). Dissertação (Mestrado em Antropologia Cultural) - PPGA/UFPE, Recife, 1999.

COMISSÃO PRÓ-ÍNDIO DE SÃO PAULO.Índios na Cidade de São Paulo.1.ed. Organização de Selma Gomes. São Paulo, 2005.

GRÜNEWALD, Rodrigo de A. Turismo, cultura e identidade étnica. In: 24a REUNIÃO BRASILEIRA DE ANTROPOLOGIA, 2004, Recife. Resumos... Recife: ABA/UFPE, 2004.

234 Marcos Alexandre dos S. ALBUQUERQUE. Os Pankararu e o Associativismo... 
MATTA, Priscila. Dois Elos da mesma corrente: Uma Etnografia da Corrida do Umbu e da Penitência entre os Pankararu. Dissertação (Mestrado em Antropologia Social) - PPGAS/USP, São Paulo, 2006. (dir.). Índios Pankararu da comunidade Real Parque de São Paulo-SP. Série BPF Brasil Passado e Futuro. Produção: Alfredo Bello. Selo: Mundo Melhor, São Paulo, 2007. CD-Rom.

SAMPAIO, Rafael. Índios urbanos enfrentam desemprego na periferia de SP. Agência Carta Maior, 7/6/2005.

SANDRONI, Carlos; VILAR, Gustavo; ACSELRAD, Maria. Torés Pankararu ontem e hoje. In: GRÜNEWALD, Rodrigo de A. (org.). Toré: regime encantado dos índios do Nordeste. Recife: Massangana, 2005.

Recebido em 13 de janeiro de 2009.

Aprovado para publicação em 23 de janeiro de 2009. 
